Correspondence

Yōko Takahashi

ytakaha@lisci.kitasato-u.ac.jp

\section{Patulibacter minatonensis gen. nov., sp. nov., a novel actinobacterium isolated using an agar medium supplemented with superoxide dismutase, and proposal of Patulibacteraceae fam. nov.}

\author{
Yōko Takahashi, ${ }^{1}$ Atsuko Matsumoto, ${ }^{2}$ Kurimi Morisaki ${ }^{1}$ \\ and Satoshi Ōmura ${ }^{1,2}$ \\ ${ }^{1}$ Kitasato Institute for Life Sciences, Kitasato University, 5-9-1 Shirokane, Minato-ku, Tokyo
108-8641, Japan \\ ${ }^{2}$ The Kitasato Institute, 5-9-1 Shirokane, Minato-ku, Tokyo 108-8642, Japan
}

\begin{abstract}
A novel Gram-positive bacterial strain, designated $\mathrm{KV}-614^{\top}$, was isolated from a soil sample using an agar medium supplemented with superoxide dismutase. Based on 16S rRNA gene sequence analysis, it was found that the strain represented a novel deep-rooting lineage within the class Actinobacteria and clustered with yet-uncultivated bacteria from terrestrial environments and some unidentified strains isolated by unique methods. The most closely related established genus was Conexibacter ( $92 \cdot 4 \%$ sequence similarity to Conexibacter woesei DSM $\left.14684^{\top}\right)$. Cells of strain $\mathrm{KV}-614^{\top}$ were rod-shaped and motile with long flagella. The strain was catalase-positive, oxidase-negative and grew under aerobic conditions. The cell-wall peptidoglycan contained meso-diaminopimelic acid as the diagnostic diamino acid and alanine and glutamic acid. The peptidoglycan acyl type was acetyl. The only detected isoprenoid quinone was demethylmenaquinone with seven isoprene units (DMK-7). Mycolic acids were not detected.

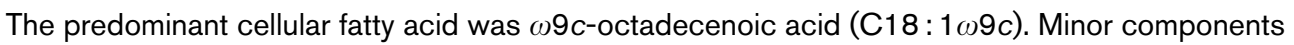
were 12-methyl tetradecanoic acid (anteiso-C15:0) and 14-methyl hexadecanoic acid (anteiso-C17:0). The DNA G +C content was $72 \mathrm{~mol} \%$. On the basis of phenotypic and genotypic characteristics, it is proposed that strain $\mathrm{KV}-614^{\top}$ represents a new genus and a novel species, Patulibacter minatonensis gen. nov., sp. nov., in the class Actinobacteria. The type strain is KV-614 ${ }^{\top}\left(=\right.$ NRRL B- $24346^{\top}=J C M 12834^{\top}=$ NBRC $\left.100761^{\top}\right)$. The creation of the family Patulibacteraceae fam. nov. is proposed to encompass the genus Patulibacter gen. nov.
\end{abstract}

\section{INTRODUCTION}

The number of micro-organisms that have been successfully identified and cultured in vitro represents only a small portion of the total existing in nature; it has been estimated that the number of known bacteria is less than $10 \%$ of the total number of bacterial species in the world (Whitman et al., 1998; Schleifer, 2004). For many unknown micro-organisms, the appropriate cultivation conditions have not yet been found. In the course of searching for factors which promote bacterial colony growth, we found that using an isolation agar medium supplemented with superoxide dismutases (SODs) increased the number of colonies isolated from a

Published online ahead of print on 9 December 2005 as DOI 10.1099/ ijs.0.63796-0.

Abbreviations: DAP, diaminopimelic acid; SOD, superoxide dismutase. The GenBank/EMBL/DDBJ accession number for the partial $16 \mathrm{~S}$ rRNA gene sequence of strain $\mathrm{KV}-614^{\top}$ is $\mathrm{AB} 193261$. soil sample, a response that was further enhanced by the addition of catalase (Takahashi et al., 2003). In this paper, we report the taxonomic characterization and classification of strain $\mathrm{KV}-614^{\mathrm{T}}$ isolated from a soil sample using agar medium supplemented with SOD.

\section{METHODS}

Isolation and cultivation conditions. Strain $\mathrm{KV}-614^{\mathrm{T}}$ was isolated from a soil sample collected at Minato-Ku, Tokyo, Japan, using an agar medium supplemented with SOD following the method of Takahashi et al. (2003). Glucose/peptone/meat extract (GPM) agar medium, consisting of $1 \%$ D-glucose (Wako Pure Chem. Ind.), $0.5 \%$ peptone (Kyokuto Seiyaku Co.), $0.5 \%$ meat extract (Kyokuto Seiyaku Co.), $0 \cdot 3 \% \mathrm{NaCl}$ and $1 \cdot 2 \%$ agar (Wako Pure Chem. Ind.) supplemented with $30 \mathrm{U} \mathrm{ml}^{-1}$ Escherichia coli SOD (Sigma), was used for strain isolation. The strain was cultured on 1/5-strength nutrient agar (1/5 NA; Difco), ISP 3 medium (Shirling \& Gottlieb, 1966), heart infusion agar, R2A agar and Todd-Hewitt agar (Difco) and yeast extract/glucose agar [YD agar; containing $1 \cdot 0 \%$ yeast 
extract (Difco), $1.0 \%$ glucose and $1.2 \%$ agar] for 7 days at $27^{\circ} \mathrm{C}$. Trypticase soy broth (BBL) was used for liquid culture. The strain was stored at $5^{\circ} \mathrm{C}$ under lyophilization.

Morphology. The morphological characteristics of the strain were observed using a transmission electron microscope (JEM-1200EXII; JEOL) after incubation for 3 days at $27^{\circ} \mathrm{C}$ in trypticase soy broth. Negative staining of cells was performed with $1 \%$ uranyl acetate. Gram-staining was performed using a Gram's stain reagent kit (Nacalai Tesque).

Physiology. Substrate utilization patterns were studied by using a GP2 microplate from the Biolog identification system. Enzyme activities were examined by using API ZYM test strips (bioMérieux). The API 20 NE test system (bioMérieux) was used for the investigation of additional physiological characteristics. Cells were grown on 1/5 NA for these tests. For determination of the temperature range for growth, bacteria were cultured on 1/5 NA medium. $\mathrm{NaCl}$ tolerance was examined using YD agar medium. The $\mathrm{pH}$ growth range was also determined using YD agar that was adjusted to $\mathrm{pH}$ values ranging between 5 and 9 with $\mathrm{HCl}$ or $\mathrm{NaOH}$. Antibiotic susceptibility was determined by placing antibiotic discs (KB Disk; Eiken) on $1 / 5$ NA plates seeded with suspensions of strain $\mathrm{KV}-614^{\mathrm{T}}$.

Chemotaxonomic characterization. Purified cell-wall preparations were obtained using the method of Schleifer \& Kandler (1972). The amino acid composition of cell-wall hydrolysates (Becker et al., 1965) was identified by TLC (Hasegawa et al., 1983). The $N$-acyl type of muramic acid was determined using the colorimetric method of Uchida \& Aida (1977). Isoprenoid quinone was extracted as described by Collins et al. (1977). The sample was analysed by HPLC with 802-SC chromatography (JASCO) using a CAPCELL PAK C18 column (Shiseido) (Tamaoka et al., 1983) and was further analysed by MS and NMR. The detection of mycolic acids was performed by TLC (Tomiyasu, 1982). Methyl esters of cellular fatty acids were prepared by direct transmethylation with methanolic hydrochloride using cells grown on trypticase soy agar at $27^{\circ} \mathrm{C}$ for 4 days and analysed on a GLC system (HP 6890; Hewlett Packard). Identification and quantification of the fatty acid methyl esters, as well as the numerical analysis of the fatty acid profiles, were performed according to the instructions for the Microbial Identification System (MIDI).

DNA $\mathbf{G}+\mathbf{C}$ content. Chromosomal DNA was prepared following the procedure of Marmur (1961) and the DNA G + C content was determined by reverse-phase HPLC according to Tamaoka \& Komagata (1984).

Phylogenetic analysis. DNA was isolated following the method of Marmur (1961). The 16S rRNA gene was amplified using primers described by Takahashi et al. (2002). Amplifications were performed in a TaKaRa thermal cycler (Takara) with an initial incubation of $1 \mathrm{~min}$ at $94{ }^{\circ} \mathrm{C}$ followed by 30 cycles of $1 \mathrm{~min}$ at $94{ }^{\circ} \mathrm{C}, 1 \mathrm{~min}$ at $50^{\circ} \mathrm{C}$ and $1.5 \mathrm{~min}$ at $72{ }^{\circ} \mathrm{C}$, followed by a 2 min final extension at $72^{\circ} \mathrm{C}$. The PCR products were purified using a QIAquick gel extraction kit (Qiagen) and were sequenced directly on a DNA sequencer (ABI PRISM 3100; Applied Biosystems) using PRISM ready reaction dye primer cycle sequencing kits (Applied Biosystems), according to the manufacturer's instructions. The 16S rRNA gene sequence was manually aligned with the corresponding sequences of representative strains and clones retrieved from the DDBJ database. CLUSTAL $\mathrm{W}$ (Thompson et al., 1994) was used to estimate evolutionary distances (the $K_{\text {nuc }}$ value of Kimura, 1980) and similarity values were used to construct the phylogenetic tree by the neighbour-joining method (Saitou \& Nei, 1987). The topology of the tree was evaluated by performing a bootstrap analysis (Felsenstein, 1985) using 1000 resamplings. The phylogenetic tree produced by the maximum-likelihood method was generated using PAUP* version $4.0 \mathrm{~b} 8$ (Swofford, 2001).

\section{RESULTS AND DISCUSSION}

\section{Cultural and morphological characteristics}

Strain KV- $614^{\mathrm{T}}$ forms flat and nearly transparent colonies with a whitish colour on 1/5 NA, ISP 3 medium and R2A agar and with a pale-yellow colour on heart infusion agar and Todd-Hewitt agar. Bacterial cells are Gram-positive and rod-shaped $(1 \cdot 2-1 \cdot 5 \times 0 \cdot 6-0 \cdot 7 \mu \mathrm{m})$. Cells are motile due to the presence of long flagella (Fig. 1).

\section{Phylogenetic analysis}

The almost-complete 16S rRNA gene sequence (1528 nt) was determined for strain $\mathrm{KV}-614^{\mathrm{T}}$. Preliminary sequence comparisons with 16S rRNA gene sequences deposited in GenBank indicated that strain KV-614 ${ }^{\mathrm{T}}$ belonged to the class Actinobacteria.

A phylogenetic tree constructed using the 16S rRNA gene sequences of strain and those of cloned and cultured relatives retrieved from GenBank is shown in Fig. 2. Based on its $16 \mathrm{~S}$ rRNA gene sequence, strain $\mathrm{KV}-614^{\mathrm{T}}$ belongs to a phylogenetic cluster consisting of uncultured bacteria from terrestrial environments and unidentified bacterial strains. The closest sequence was that of bacterium Ellin 5025 (93.2\% similarity; Joseph et al., 2003).

A neighbour-joining phylogenetic tree constructed from the $16 \mathrm{~S}$ rRNA gene sequence of strain $\mathrm{KV}-614^{\mathrm{T}}$ and those of other recognized species is shown in Fig. 3. Strain KV-614 ${ }^{\mathrm{T}}$ represents a novel lineage within the order Rubrobacterales of the

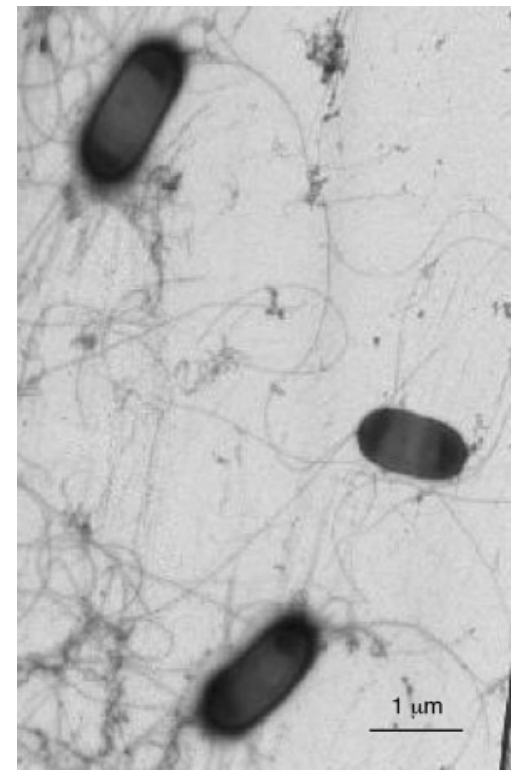

Fig. 1. Transmission electron micrograph of negatively stained cells of strain $\mathrm{KV}-614^{\top}$. The bacterial cells exhibit long flagella. Bar, $1 \mu \mathrm{m}$. 


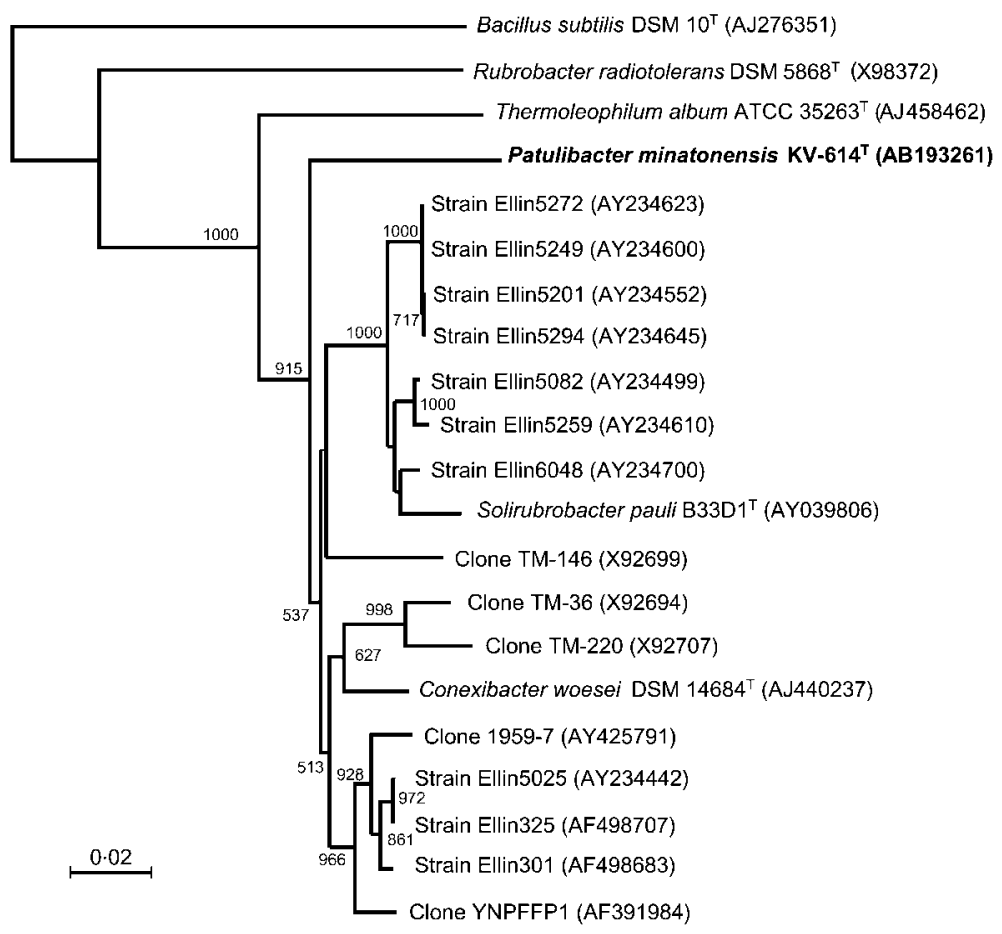

Fig. 2. Neighbour-joining phylogenetic tree based on 16S RNA gene sequences of strain $\mathrm{KV}-614^{\top}$ and its closest clonal and cultured relatives. Clones prefixed 'TM' were from a peat bog (Rheims et al., 1996, 1999) and strains prefixed 'Ellin' were from Australian soils (Sait et al., 2002; Joseph et al., 2003). The sequences of clones YNPFFP1 and 1959-7 were available from public databases. Numbers at nodes are bootstrap values based on 1000 resamplings; only values higher than 500 are shown. The tree was rooted with Bacillus subtilis. Bar, 20 inferred nucleotide substitutions per 1000 nucleotides.

class Actinobacteria (Stackebrandt et al., 1997), adjacent to the genera Conexibacter (Monciardini et al., 2003) and Solirubrobacter (Singleton et al., 2003). The 16S rRNA gene sequence similarity of strain $\mathrm{KV}-614^{\mathrm{T}}$ to Conexibacter woesei DSM $14684^{\mathrm{T}}$ is $92 \cdot 4 \%$ and it shows $89 \cdot 7 \%$ similarity to that of Solirubrobacter pauli $\mathrm{B} 33 \mathrm{D} 1^{\mathrm{T}}$. The tree constructed by the

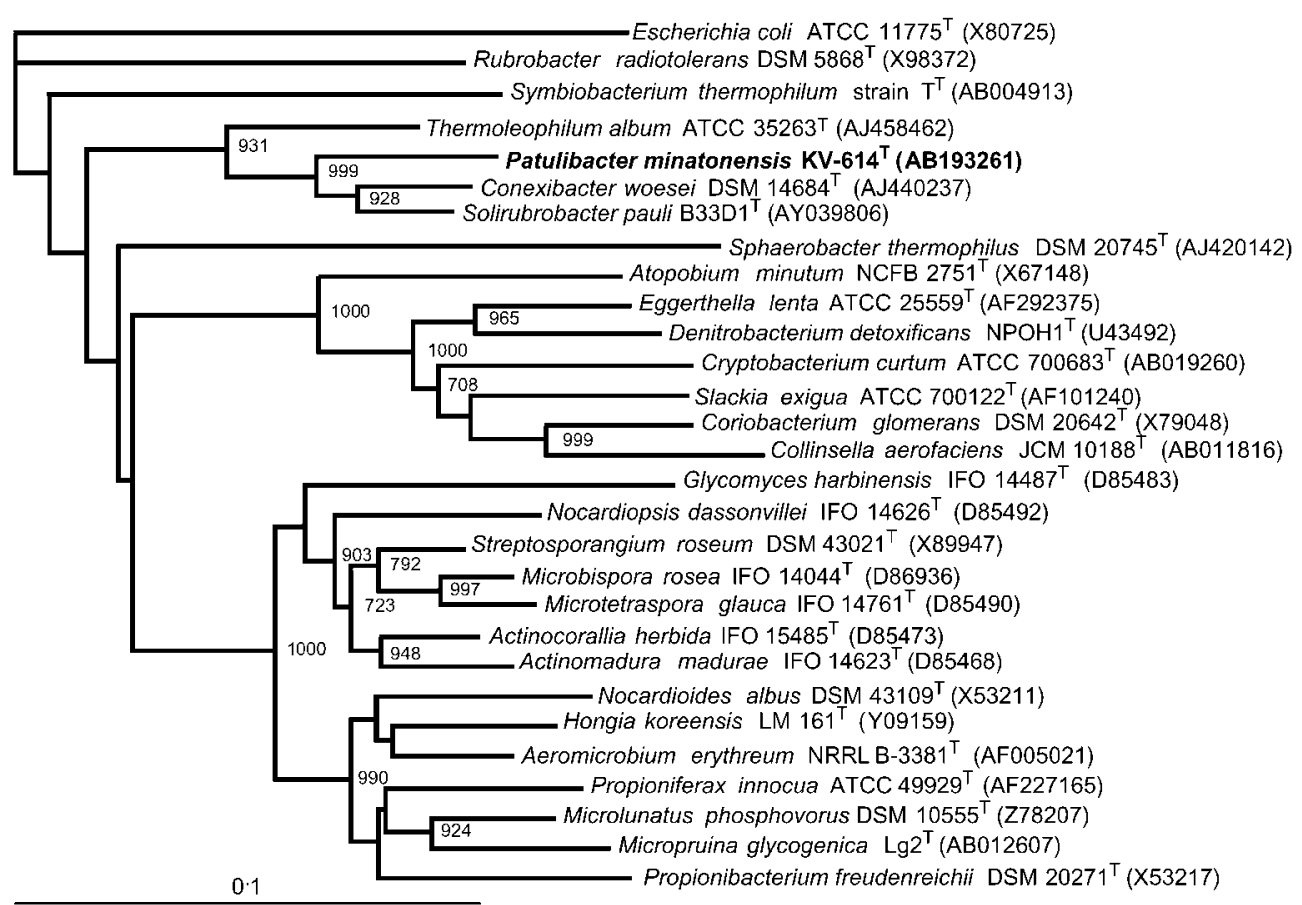

Fig. 3. Phylogenetic tree showing the position of strain $\mathrm{KV}-614^{\top}$ based on $16 \mathrm{~S}$ rRNA gene sequences. Numbers at nodes indicate the level of bootstrap support based on neighbour-joining analysis of 1000 resampled datasets. Only values higher than 700 are shown. The tree was rooted with Escherichia coli. Bar, 10 inferred nucleotide substitutions per 100 nucleotides. 
maximum-likelihood method supported this result (data not shown).

\section{Chemotaxonomic characteristics}

To characterize strain KV-614 ${ }^{\mathrm{T}}$ further, bacterial cell chemical constituents were analysed. Cell-wall peptidoglycan contained meso-diaminopimelic acid (DAP) as the diagnostic diamino acid and alanine and glutamic acid. The peptidoglycan appeared to be of the Al $\gamma$ type (based on meso-DAP, direct cross-linkage). The peptidoglycan was of the acetyl type. The isoprenoid quinone was demethylmenaquinone with seven isoprene units (DMK-7), which was detected as the only component by HPLC. DMK-7 has also been found in Enterococcus faecalis (Hiraishi, 1988), Pasteurella and Haemophilus (Kroppenstedt \& Mannheim, 1989); however, this unique isoprenoid quinone has been not reported previously for established genera of the class Actinobacteria. Mycolic acids were not detected. The predominant cellular fatty acid components were $\omega 9 c$-octadecenoic acid (oleic acid, $\mathrm{C} 18: 1 \omega 9 c, 63 \cdot 2 \%$ ), 12-methyl tetradecanoic acid (anteiso-C15:0, 9.8\%), 14-methyl hexadecanoic acid (anteiso-C17: 0, 7·7\%), hexadecanoic acid (C16:0, $4 \cdot 5 \%$ ) and octadecanoic acid (C18:0, $4 \cdot 3 \%)$. There was no match to any entry in the TDBA50 MIS library, further supporting the classification of strain $\mathrm{KV}-614^{\mathrm{T}}$ as a member of a novel genus and species. The DNA G $+\mathrm{C}$ content of strain $\mathrm{KV}-614^{\mathrm{T}}$ was $72 \mathrm{~mol} \%$.

\section{Physiological characteristics}

Strain $\mathrm{KV}-614^{\mathrm{T}}$ was aerobic, catalase-positive, oxidasenegative and able to reduce nitrate to nitrite. It did not grow on media containing $\geqslant 2 \%(\mathrm{w} / \mathrm{v}) \mathrm{NaCl}$. The $\mathrm{pH}$ range for growth was 6-8. The temperature range for growth was $16-$ $28^{\circ} \mathrm{C}$ and the optimum temperature for growth was $24-27^{\circ} \mathrm{C}$.

\section{Taxonomic conclusions}

On the basis of phylogenetic analysis, strain KV-614 ${ }^{\mathrm{T}}$ belongs to the order Rubrobacterales of the subclass Rubrobacteridae (Stackebrandt et al., 1997). An A residue at position 906 (E. coli sequence; Brosius et al., 1978) and a U residue at position 955 , characteristics of members of the subclass Rubrobacteridae, were confirmed to be present in the $16 \mathrm{~S}$ rRNA gene sequence of strain KV-614 ${ }^{\mathrm{T}}$. The characteristic pattern of $16 \mathrm{~S}$ rRNA gene sequence signature nucleotides of the subclass Rubrobacteridae (Stackebrandt, 2004), 127-234 (G-C), 291-309 (U-A), 955-1225 (U-A), 1115-1185 (C-G) and 1410-1490 (A-U), was also present.

Table 1 shows the phenotypic characteristics of strain KV$614^{\mathrm{T}}$ and members of two phylogenetically related genera, Conexibacter and Solirubrobacter. Like strain KV- $614^{\mathrm{T}}$, C. woesei has meso-DAP as the diagnostic diamino acid in the cell-wall peptidoglycan and also produces long flagella, but it clearly differs in the major menaquinone $\mathrm{MK}-7\left(\mathrm{H}_{4}\right)$ and predominant fatty acids. S. pauli is distinguished from strain $\mathrm{KV}-614^{\mathrm{T}}$ in that it has non-motile cells and a different fatty acid content. Data on isoprenoid quinones and cell-wall peptidoglycan amino acids are not yet available for this genus. On the basis of phylogenetic analysis and phenotypic characteristics, we propose that strain $\mathrm{KV}-614^{\mathrm{T}}$ represents a novel genus and species, Patulibacter minatonensis gen. nov., sp. nov. (type strain KV-614 ${ }^{\mathrm{T}}=\mathrm{NRRL} \mathrm{B}-24346^{\mathrm{T}}=\mathrm{JCM}$ $12834^{\mathrm{T}}=$ NBRC $\left.100761^{\mathrm{T}}\right)$.

At present, the order Rubrobacterales (Stackebrandt et al., 1997) contains four families, Rubrobacteraceae, Conexibacteraceae, Solirubrobacteraceae and Thermoleophilaceae (Stackebrandt, 2004). Based on the distinct phylogenetic position of Patulibacter minatonensis gen. nov., sp. nov. within the order Rubrobacterales and the differences observed in the pattern of $16 \mathrm{~S}$ rRNA gene sequence signature nucleotides, a new family, Patulibacteraceae fam. nov., is proposed.

Table 1. Differential characteristics of strain $\mathrm{KV}-614^{\top}$ and members of related genera

Strains: 1, KV-614 ${ }^{\mathrm{T}}$; 2, Conexibacter woesei ID $131577^{\mathrm{T}}$ (data from Monciardini et al., 2003); 3, Solirubrobacter pauli B33D1 ${ }^{\mathrm{T}}($ Singleton et al., 2003). ND, Not determined; -, negative; +, positive.

\begin{tabular}{|c|c|c|c|}
\hline Characteristic & 1 & 2 & 3 \\
\hline Length of rods $(\mu \mathrm{m})$ & $1 \cdot 2-1 \cdot 5$ & $0 \cdot 9-1 \cdot 2$ & $1 \cdot 4$ \\
\hline Motility & Motile, long flagella & Motile, long flagella & Non-motile \\
\hline Optimum growth temperature $\left({ }^{\circ} \mathrm{C}\right)$ & $24-27$ & $28-37$ & $28-30$ \\
\hline $\mathrm{pH}$ range & $6-8$ & $7-7 \cdot 5$ & $6-7 \cdot 7$ \\
\hline Oxidase & - & + & - \\
\hline Major fatty acids $(>8 \%)$ & $\begin{array}{c}\mathrm{C} 18: 1 \omega 9 c(63 \%) ; \\
\mathrm{a}-\mathrm{C} 15: 0(10 \%) \\
\mathrm{a}-\mathrm{C} 17: 0(8 \%)\end{array}$ & $\begin{array}{l}\mathrm{C} 18: 1 \omega 9 c(41 \%) ; \\
\text { i-C16:0 }(16 \%) ; \\
\text { C17: } 1 \omega 9 c(14 \%) ; \\
\text { C16:0 }(13 \%)\end{array}$ & $\begin{array}{l}\mathrm{i}-\mathrm{C} 16: 0(54 \%) \\
\mathrm{C} 18: 1 \omega 9 c(36 \%)\end{array}$ \\
\hline Diagnostic amino acid in peptidoglycan & meso-DAP & meso-DAP & $\mathrm{ND}$ \\
\hline Isoprenoid quinone & DMK-7 & $\mathrm{MK}-7\left(\mathrm{H}_{4}\right)$ & ND \\
\hline
\end{tabular}




\section{Description of Patulibacter gen. nov.}

Patulibacter (Pat.ul.i.bac'ter. L. adj. patulus spreading; N.L. masc. n. bacter from Gr. n. baktron a rod; N.L. masc. n. Patulibacter bacterium with spreading growth).

Cells are Gram-positive, non-endospore-forming rods. Bacterial respiration is aerobic. Cell-wall peptidoglycan contains meso-DAP as the diagnostic diamino acid and alanine and glutamic acid. The peptidoglycan is of the acetyl type. The fatty acid profile is dominated by C18: $1 \omega 9 c$. Mycolic acids are absent. The predominant isoprenoid quinone is DMK-7. The DNA G + C content is $72 \mathrm{~mol} \%$. The type species is Patulibacter minatonensis sp. nov.

\section{Description of Patulibacter minatonensis sp. nov.}

Patulibacter minatonensis (mi.na.to.nen'sis. N.L. masc. adj. minatonensis pertaining to Minato-ku, the ward of Tokyo, Japan, where the type strain was isolated).

Exhibits the following properties in addition to those given in the genus description. Forms flat and nearly transparent colonies with a whitish or pale yellow colour. Cells are $1 \cdot 2-1 \cdot 5 \times 0 \cdot 6-0 \cdot 7 \mu \mathrm{m}$ in size, motile by long flagella, catalasepositive and oxidase-negative. Utilizes the following substrates: dextrin, inulin, mannan, $\mathrm{N}$-acetyl-D-mannosamine, L-arabinose, D-arabitol, cellobiose, D-fructose, L-fucose, Dgalactose, D-galacturonic acid, $\alpha$-D-glucose, myo-inositol, maltose, maltotriose, D-mannitol, D-mannose, D-melezitose, methyl $\alpha$-D-galactoside, methyl $\beta$-D-glucoside, methyl $\alpha$-Dglucoside, methyl $\alpha$-D-mannoside, D-psicose, L-rhamnose, salicin, sedoheptulosan, turanose, $\alpha$-hydroxybutyric acid, lactamide, D-lactic acid methyl ester, L-lactic acid, L-serine, 2,3-butanediol, adenosine, inosine, uridine, adenosine $5^{\prime}$ monophosphate, fructose 6-phosphate, glucose 1-phosphate, glucose 6-phosphate, DL- $\alpha$-glycerol phosphate, D-ribose, Dtagatose, D-xylose, acetic acid, propionic acid, D-alanine, putrescine, maltose, potassium gluconate, adipic acid and Lmalic acid. Shows the following enzyme activities: alkaline phosphatase, elastase (C4), elastase lipase (C8), lipase (C4), leucine arylamidase, acid phosphatase and naphthol-ASBI-phosphohydrolase. Negative result in Biolog substrate panels, API ZYM enzyme assay and API NE gallery tests for: $\alpha$-cyclodextrin, $\beta$-cyclodextrin, glycogen, Tween 40 , Tween 80 , amygdalin, arbutin, gentiobiose, D-gluconic acid, $\alpha$-D-lactose, lactulose, D-melibiose, methyl $\beta$-D-galactoside, 3 -methyl glucose, palatinose, D-raffinose, D-sorbitol, stachyose, sucrose, $\mathrm{D}$-trehalose, xylitol, $\beta$-hydroxybutyric acid, $\gamma$-hydroxybutyric acid, $p$-hydroxyphenylacetic acid, $\alpha$ ketoglutaric acid, $\alpha$-ketovaleric acid, D-malic acid, methylpyruvate, monomethyl succinate, pyruvic acid, succinamic acid, succinic acid, $\mathrm{N}$-acetyl L-glutamic acid, alaninamide, L-alanine, L-alanylglycine, L-asparagine, L-glutamic acid, glycyl L-glutamic acid, L-pyroglutamic acid, glycerol, 2' deoxyadenosine, thymidine, thymidine $5^{\prime}$-monophosphate, uridine 5 '-monophosphate, $N$-acetyl-D-glucosamine, ndecanoic acid, citric acid, phenylacetate, valine arylamidase, cystine arylamidase, trypsin, chymotrypsin, $\alpha$-galactosidase, $\beta$-glucuronidase, $\alpha$-glucosidase, $\beta$-glucosidase, $N$-acetyl$\beta$-glucosaminidase, $\alpha$-mannosidase, $\alpha$-fucosidase, nitrate reduction, tryptophan degradation, glucose fermentation, gelatin hydrolysis, arginine dihydrolase, urease and $\beta$ galactosidase. Does not grow on media containing $2 \%(\mathrm{w} / \mathrm{v})$ $\mathrm{NaCl}$. The $\mathrm{pH}$ range for growth is 6-8. The temperature range for growth is $16-28^{\circ} \mathrm{C}$. The type strain is susceptible to tetracycline $(30 \mu \mathrm{g})$, polymyxin $\mathrm{B}(300 \mathrm{U})$, amikacin $(30 \mu \mathrm{g})$, chloramphenicol $(30 \mu \mathrm{g})$, erythromycin $(15 \mu \mathrm{g})$, ciprofloxacin $(5 \mu \mathrm{g})$, tobramycin $(10 \mu \mathrm{g})$, vancomycin $(30 \mu \mathrm{g})$, kanamycin $(30 \mu \mathrm{g})$, gentamicin $(10 \mu \mathrm{g})$, ampicillin $(10 \mu \mathrm{g})$ and imipenem $(10 \mu \mathrm{g})$. Cells are resistant to aztreonam $(30 \mu \mathrm{g})$, ceftazidime $(30 \mu \mathrm{g})$, nalidixic acid $(1 \mu \mathrm{g})$, norfloxacin $(10 \mu \mathrm{g})$ and oxacillin $(1 \mu \mathrm{g})$. The DNA G $+\mathrm{C}$ content is $72 \mathrm{~mol} \%$.

The type strain, KV-614 ${ }^{\mathrm{T}}\left(=\mathrm{NRRL} \mathrm{B}-24346^{\mathrm{T}}=\mathrm{JCM} 12834^{\mathrm{T}}\right.$ $=$ NBRC $\left.100761^{\mathrm{T}}\right)$, was isolated from soil.

\section{Description of Patulibacteraceae fam. nov.}

Patulibacteraceae (Pat.ul.i.bact.era'ce.ae. N.L. masc. n. Patulibacter type genus of the family; -aceae ending to denote a family; N.L. fem. pl. n. Patulibacteraceae the Patulibacter family).

Cells are Gram-positive and non-endospore-forming. Cellwall peptidoglycan is based upon meso-DAP. The main isoprenoid quinone is demethylmenaquinone. Mycolic acids are absent. The pattern of $16 \mathrm{~S}$ rRNA gene sequence signature nucleotides of members of the family consists of 52-359 (CG), 98 (A), 139 (G), 144-178 (C-G), 370-391 (C-G), 580-761 (U-A), 590-649 (U-A), 600-638 (U-G), 670-736 (A-U), 953-1228 (G-C), 954-1226 (G-C), 999-1041 (UA), 657-749 (U-A), 681-709 (U-A), 941-1342 (A-U), 1051-1207 (G-C) and 1311-1326 (A-U). Phylogenetically, the family is a member of the class Actinobacteria, subclass Rubrobacteridae, order Rubrobacterales. The type genus is Patulibacter.

\section{ACKNOWLEDGEMENTS}

The authors wish to thank Yuzuru Iwai and Yuji Uchida of The Kitasato Institute for their kind help and menaquinone analysis, respectively, and also Akiko Kageyama of Kitasato Institute for Life Sciences, Kitasato University, for amino acid analysis. This research was supported in part by a grant from the 21st Century COE Program of the Ministry of Education, Culture, Sports, Science and Technology (MEXT), Japan and Grants-in-Aid for Scientific Research of JSPS.

\section{REFERENCES}

Becker, B., Lechevalier, M. P. \& Lechevalier, H. A. (1965). Chemical composition of cell-wall preparations from strains of various formgenera of aerobic actinomycetes. Appl Microbiol 13, 236-243.

Brosius, J., Palmer, M. L., Kennedy, P. J. \& Noller, H. F. (1978). Complete nucleotide sequence of a $16 \mathrm{~S}$ ribosomal RNA gene from Escherichia coli. Proc Natl Acad Sci U S A 75, 4801-4805. 
Collins, M. D., Pirouz, T., Goodfellow, M. \& Minnikin, D. E. (1977). Distribution of menaquinones in actinomycetes and corynebacteria. $J$ Gen Microbiol 100, 221-230.

Felsenstein, J. (1985). Confidence limits on phylogenies: an approach using the bootstrap. Evolution 39, 783-791.

Hasegawa, T., Takizawa, M. \& Tanida, S. (1983). A rapid analysis for chemical grouping of aerobic actinomycetes. J Gen Appl Microbiol 29, 319-322.

Hiraishi, A. (1988). High-performance liquid chromatographic analysis of demethylmenaquinone and menaquinone mixtures from bacteria. J Appl Bacteriol 64, 103-105.

Joseph, S. J., Hugenholtz, P., Sangwan, P., Osborne, C. A. \& Janssen, P. H. (2003). Laboratory cultivation of widespread and previously uncultured soil bacteria. Appl Environ Microbiol 69, 7210-7215.

Kimura, M. (1980). A simple method for estimating evolutionary rates of base substitutions through comparative studies of nucleotide sequences. J Mol Evol 16, 111-120.

Kroppenstedt, R. M. \& Mannheim, W. (1989). Lipoquinones in members of the family Pasteurellaceae. Int J Syst Bacteriol 39, 304-308.

Marmur, J. (1961). A procedure for the isolation of deoxyribonucleic acid from microorganisms. J Mol Biol 3, 208-218.

Monciardini, P., Cavaletti, L., Schumann, P., Rohde, M. \& Donadio, S. (2003). Conexibacter woesei gen. nov., sp. nov., a novel representative of a deep evolutionary line of descent within the class Actinobacteria. Int J Syst Evol Microbiol 53, 569-576.

Rheims, H., Sproer, C., Rainey, F. A. \& Stackebrandt, E. (1996). Molecular biological evidence for the occurrence of uncultured members of the actinomycete line of descent in different environments and geographical locations. Microbiology 142, 2863-2870.

Rheims, H., Felske, A., Seufert, S. \& Stackebrandt, E. (1999). Molecular monitoring of an uncultured group of the class Actinobacteria in two terrestrial environments. J Microbiol Methods 36, 65-75.

Sait, M., Hugenholtz, P. \& Janssen, P. H. (2002). Cultivation of globally distributed soil bacteria from phylogenetic lineages previously only detected in cultivation-independent surveys. Environ Microbiol 4, 654-666.

Saitou, N. \& Nei, M. (1987). The neighbor-joining method: a new method for reconstructing phylogenetic trees. Mol Biol Evol 4, 406-425.

Schleifer, K. H. (2004). Microbial diversity: facts, problems and prospects. Syst Appl Microbiol 27, 3-9.
Schleifer, K. H. \& Kandler, O. (1972). Peptidoglycan types of bacterial cell walls and their taxonomic implications. Bacteriol Rev 36, 407-477.

Shirling, E. B. \& Gottlieb, D. (1966). Methods for characterization of Streptomyces species. Int J Syst Bacteriol 16, 313-340.

Singleton, D. R., Furlong, M. A., Peacock, A. D., White, D. C., Coleman, D. C. \& Whitman, W. B. (2003). Solirubrobacter pauli gen. nov., sp. nov., a mesophilic bacterium within the Rubrobacteridae related to common soil clones. Int J Syst Evol Microbiol 53, 485-490.

Stackebrandt, E. (2004). Will we ever understand? The undescribable diversity of the prokaryotes. Acta Microbiol Immunol Hung 51, 449-462.

Stackebrandt, E., Rainey, F. A. \& Ward-Rainey, N. L. (1997) Proposal for a new hierarchic classification system, Actinobacteria classis nov. Int J Syst Bacteriol 47, 479-491.

Swofford, D. (2001). PAUP*, Phylogenetic Analysis Using Parsimony ( ${ }^{*}$ and other methods), version 4.0b8. Sunderland, MA: Sinauer.

Takahashi, Y., Matsumoto, A., Seino, A., Ueno, J., Iwai, Y. \& Ōmura, S. (2002). Streptomyces avermectinius sp. nov., an avermectin-producing strain. Int J Syst Evol Microbiol 52, 2163-2168.

Takahashi, Y., Katoh, S., Shikura, N., Tomoda, H. \& Ōmura, S. (2003). Superoxide dismutase produced by soil bacteria increases bacterial colony growth from soil samples. J Gen Appl Microbiol 49, 263-266.

Tamaoka, J. \& Komagata, K. (1984). Determination of DNA base composition by reversed-phase high-performance liquid chromatography. FEMS Microbiol Lett 25, 125-128.

Tamaoka, J., Katayama-Fujimura, Y. \& Kuraishi, H. (1983). Analysis of bacterial menaquinone mixtures by high performance liquid chromatography. J Appl Bacteriol 54, 31-36.

Thompson, J. D., Higgins, D. G. \& Gibson, T. J. (1994). CLUSTAL W: improving the sensitivity of progressive multiple sequence alignment through sequence weighting, position-specific gap penalties and weight matrix choice. Nucleic Acids Res 22, 4673-4680.

Tomiyasu, I. (1982). Mycolic acid composition and thermally adaptative changes in Nocardia asteroides. J Bacteriol 151, 828-837.

Uchida, K. \& Aida, K. (1977). Acyl type of bacterial cell wall: its simple identification by colorimetric method. J Gen Appl Microbiol 23, 249-260.

Whitman, W. B., Coleman, D. C. \& Wiebe, W. J. (1998). Prokaryotes: the unseen majority. Proc Natl Acad Sci U S A 95, 6578-6583. 